\title{
TECHNOLOGY FOR MANUFACTURE OF GAS-AND-OIL LINE PIPES USING HIGH-FREQUENCY METHOD OF WELDING AT COMPANY «Interpipe NMPP»
}

\author{
Yu.N. ANTIPOV ${ }^{1}$, E.V. DMITRENKO ${ }^{1}$, A.V. KOVALENKO ${ }^{1}$, S.A. GORYANOJ ${ }^{1}$, \\ A.A. RYBAKOV ${ }^{2}$, S.E. SEMYONOV ${ }^{2}$ and T.N. FILIPCHUK ${ }^{2}$ \\ ${ }^{1}$ PJSC «Interpipe «Novomoskovsky Pipe Plant» \\ 115 Suchkov Str., 51200, Novomoskovsk, Ukraine. E-mail: info@nmpp.interpipe.biz \\ ${ }^{2}$ E.O. Paton Electric Welding Institute, NASU
}

11 Bozhenko Str., 03680, Kiev, Ukraine. E-mail: office@paton.kiev.ua

\begin{abstract}
Considered are the technological peculiarities of current production of gas-and-oil line pipes of 159 to $530 \mathrm{~mm}$ diameter using high-frequency method of welding at PJSC «Interpipe NMPP». After modernization performed, preparation of welding edges of coiled strip is carried out by milling. Advanced structural-andtechnological solutions are used for pipe welding and molding. Local heat treatment of a zone of longitudinal weld is introduced. A section was organized for complex non-destructive testing, including ultrasonic (pipe body and, in addition, weld metal, near-edge zones of welded joint and end section of the pipe), as well as magnetic particles testing of machined edges. Deposition of corrosion-resistant coating on external surface of the pipe is carried out. Information technologies and automated systems are used in regulation of production processes during quality control and tracking of pipes. Applied technology allows manufacturing of gas-and-oil line pipes of medium diameter in a wide range of grade schedule in accordance with the requirements of current domestic and foreign reference documents. High quality and safety of manufactured gas-and-oil line pipes are verified by the documents of authorized certification centers, as well as by the results of performed full-scale tests of pipe specimens before fracture. Pipes of «Interpipe NMPP» production are allowed for application in the systems of main gas-and-oil pipelines in CIS, as well as in far-abroad countries, by authorized accreditation bodies. 5 Ref., 5 Tables, 5 Figures.
\end{abstract}

$\boldsymbol{K} \boldsymbol{e} \boldsymbol{y} \boldsymbol{w} \boldsymbol{o r d} \boldsymbol{s}:$ gas-and-oil line pipe, medium diameter, production, technology, edge preparation, high-frequency welding, local heat treatment, non-destructive testing, schedule, specification, tests, certification, accreditation

Production of gas-and-oil line pipes using high-frequency welding was organized at Novomoskovsk Pipe Plant («Interpipe NMPP» company) in 1965. Technological process of production mastered in that period was typical at application of high-frequency (HF) method of welding and lied in feeding of coil of up to $20 \mathrm{t}$ weight, straightening, cutting out of end sections and joining of adjacent strips using butt welding machine, cutting of side edges by circular knifes, roll molding, welding (using induction heating, fusion and upsetting of the edges), removal of flash and division of «endless» pipe for specified lengths. Further, the welded pipes were subjected to 3D thermal flame treatment by normalizing mode, machining of edges, necessary finishing operation, NDT, mechanical and hydraulic tests.

For the last years, the Plant accumulated significant technological experience of production of gas-and-oil line pipes of medium diameter. Till 2005 more than $20 \mathrm{mln} \mathrm{t}$ of gas-and-oil line pipes of $159-530 \mathrm{~mm}$ diameter were manufactured using HF welding based on specifications and standards of former USSR and then RF, Ukraine and others countries, and they are operated in different systems of main pipelines.

Nevertheless, signs of obsolescence of the plant technology from advanced foreign analogues appeared in the 1990s of the last century under conditions of transfer to market relationships. Pipe production volumes decreased and world marketing of manufactured products became difficult. Some consumers had doubts as for safety of HF-welded pipes due to limited capabilities of accepted system of NDT.

Set of measures for significant technological modernization of production of HF-welded pipes was taken at «Interpipe NMPP» after 2005 in order to expand schedule, provide for the requirements of current world standards, reduce prime cost, further improve quality and safety, and, as a result, competitiveness of the pipe products. Modernizing of technological equipment was carried out considering advanced foreign experience and recommendations of the E.O. Paton Electric Welding Institute. Novel technological equip- 
ment was delivered by enterprises of Austria, Great Britain, USA, Germany, France, Korea, Holland and Czech Republic.

Sections of a line of $159-530 \mathrm{~mm}$ pipe welding mill used for preparation of side edges, molding, welding and removal of external and internal burr were modernized and local heat treatment (LHT) of welded joint was introduced. Areas of current NDT and external corrosion-resistant coating of pipes were organized and automated information system was embedded. Production of inch series pipes of $355.9,406.4$ and $508 \mathrm{~mm}$ diameter was mastered and calibration of $530 \mathrm{~mm}$ diameter pipes was improved.

This paper considers current state, technological peculiarities, achievements and capabilities of production of $\mathrm{HF}$-welded gas-and-oil line pipes at indicated enterprise.

Milling of the side edges of coil led strip was introduced after modernizing of technological equipment. Edge milling machine provides for cutting of a layer of metal of side edges for up to $10 \mathrm{~mm}$ width, which could have technological defects (flashes and cleavages after circular knifes treatment), as well as defects of metallurgical production (tears, laminations, split cracks). Also, treatment of edges by milling completely eliminates structural and geometrical inhomogenieties of the edge surface (plastic collapse, shear, cleavage), which have destabilizing effect on process of further welding.

Edge milling machine allows receiving accurate width of a strip along its whole length with allowable deviation $\pm 0.25 \mathrm{~mm}$, that provides for optimum width along the whole length, and, respectively, rises stability of bringing together of edges in a closed pass of welding stand. This improves weld quality and ensures accuracy of pipe geometry parameters. The edge milling machine is equipped with automatic strip-width gouge providing readings displaying.

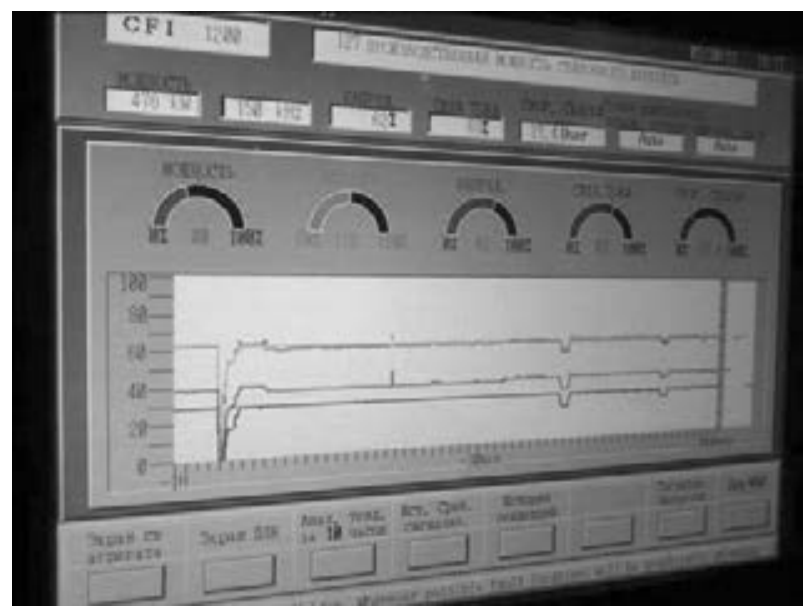

Figure 1. Control of parameters of HF welding of pipes
New welding generator, allowing pipe welding by currents of $150 \mathrm{kHz}$ frequency, was installed instead of earlier applied $10 \mathrm{kHz}$ current source. This permitted process stabilization and performance of welding in accordance with the requirements of foreign standards [1]. In addition, increased current frequency reduces HAZ and decreases depth of current penetration in the part. The generator is equipped with intelligent automatic diagnostics system, having capability of graphic displaying of the main welding process parameters in real-time mode, i.e. power takeoff, voltage, welding speed (Figure 1). Automatic control of the parameters of HF welding process during pipe manufacture is carried out based on control of metal temperature in a zone of edge surface melting using laser and fiber-optic device. Automatic devices allow significantly reducing negative effect of deviations from welding conditions on parameters of mode and weld quality.

Weld constricting five-roll stand is mounted in the welding zone. Such a structure provides for accuracy and stability of pipe geometry parameters due to application of two side, one bottom support and two near-edge rolls in the closed pass. In turn, the accuracy of pipe profile geometry in the welding pass ensures stability of one of the most important parameters of HF welding, namely, edge upsetting, as well as eliminates formation of «edge displacement» defect in pipe billet. The five-roll welding stand is equipped with the trimmers providing quality removal of outside and inside flash.

Installed computer system registers the results of ultrasonic testing of quality of removal of internal flash and thickness of wall in place of its removal in real-time mode (with print-out capability).

Technology of LHT of pipe welded joint at width of heating zone not less than $20 \mathrm{~mm}$ was introduced instead of volume one. New automatic medium-frequency induction units (Figure 2) were mounted. Normalizing mode during LHT provides for relieve of residual stresses and re-solidification of microstructure, that determine rise and stability of mechanical properties of the welded joint. Base metal properties in LHT remain virtually the same, technology of production of coiled stock provides its high quality indices.

Equipment of a line for heat treatment of pipe welds is equipped with systems of automatic regulation and control for stabilizing of heating temperature with $\pm 20{ }^{\circ} \mathrm{C}$ accuracy, as well as radial tracking of position of welded joint in zone of regulation $\left( \pm 15^{\circ}\right)$.

Indicated above automated systems for control, as well as regulation (stabilizing and regis- 
tration) of parameters of industrial processes, based on application of current information technologies, are the integral part of a step system of technological and acceptance control of the pipes existing at the Plant.

Technological inspection includes:

- incoming inspection of coiled steel;

- visual inspection of pipe surface;

- NDT of welded joint integrity and quality of flash removal in a mill line;

- sampling of bend test specimens from start pipes at technological transfers (change of diameter, wall thickness, steel melting);

- continuous and periodic inspection of each step of process of pipe production by workshop and technical control department personnel, respectively.

Acceptance inspection provides for:

- NDT of pipe metal integrity by means of external examination and application of physical methods. New equipment for ultrasonic testing allows inspection of the whole pipe body ( $\mathrm{Fi}^{-}$ gure 3). Additionally, ultrasonic testing of weld metal and adjacent to it near-edge zones, as well as pipe end sections is carried out. Surface integrity of pipe edges is evaluated by means of magnetic particle testing;

- check of pipe mechanical properties;

- metallographic inspection of welded joint after LHT;

- inspection of geometry parameters of pipe edges and body, including the areas of internal and external flash removal;

- hydraulic testing of pipes.

Automated system used for traceability, accounting of production and control of product quality was implemented. New equipment allows documentation of technological parameters of the pipe production process in reference to number of each pipe. Registration of diameter, wall thickness, steel grade, welding rate, takeoff power and temperature of edges in fusion zone, results of technological ultrasonic testing, temperature of welded joint heat treatment; results of hydraulic tests (pressure, time of soaking, strength evaluation), results of other acceptance tests (mechanical, chemical, non-destructive) is carried out.

Besides, the system provides for automation of the process of receiving of reliable and timely information on state of product production; revealing of mismatch of parameters of technological process, quality of products and taking of effective corrective actions; accumulation and processing of statistical data on quality of metal delivered into production and output products on different criteria; drawing of document for output products and quality certificates in paper and electronic forms.

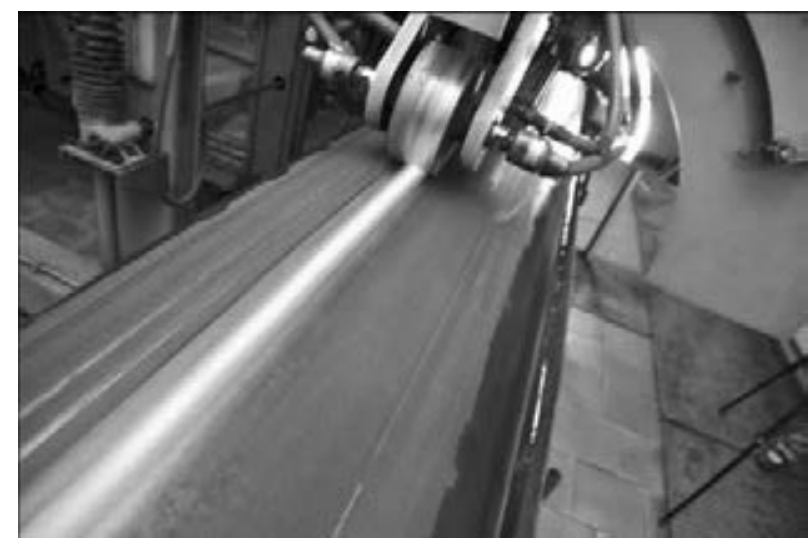

Figure 2. LHT of pipe welded joint

Corrosion-resistant coatings are deposited over external surface of 114-530 diameter pipes, which had undergone full technological cycle and were declared valid during acceptance. Insulating materials are applied after performance of preliminary certification tests. Depending on customer requirements, corrosion-resistant coatings of different compositions are deposited:

- one-layer epoxy coating of up to $800 \mu \mathrm{m}$ thickness;

- double-layer coating with application of adhesion layers and polyethylene at total thickness of the coating from 1.8 to $5.0 \mathrm{~mm}$;

- three-layer coating based on ground (epoxy primer), adhesion and polyethylene layers. Total thickness of the coating makes from 2 to $5 \mathrm{~mm}$.

Acceptance of pipes with coatings is carried out considering test performance according to specified technical requirements. Results of coating tests are registered in certificates of pipe quality.

Selection of suppliers of materials for corrosion-resistant coatings is carried out considering performance of wide complex of tests for the purpose of determination of indices of dielectric uniformity, adhesion to steel, area of cathode detachment, transient resistance, cracking resistance, resistant to temperature cycling etc. Pipes having technical characteristics of corrosion-resistance coatings, which correspond to the re-

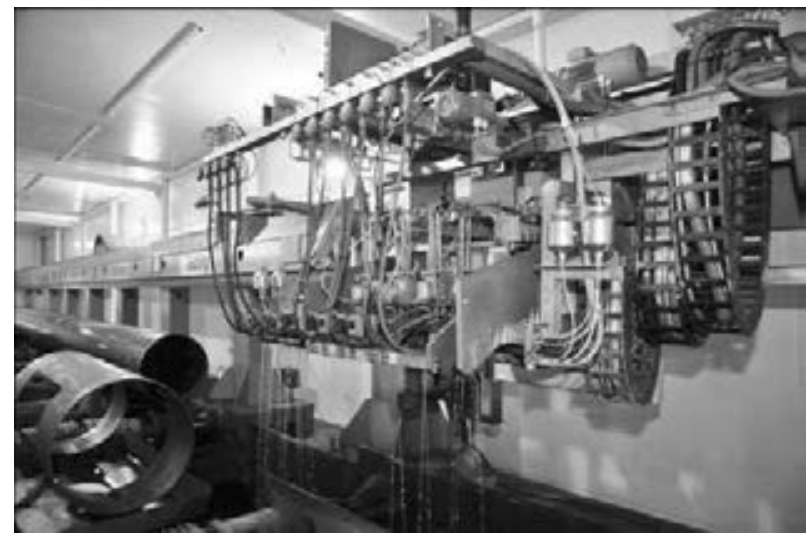

Figure 3. System for ultrasonic testing of base metal and pipe welded joint 

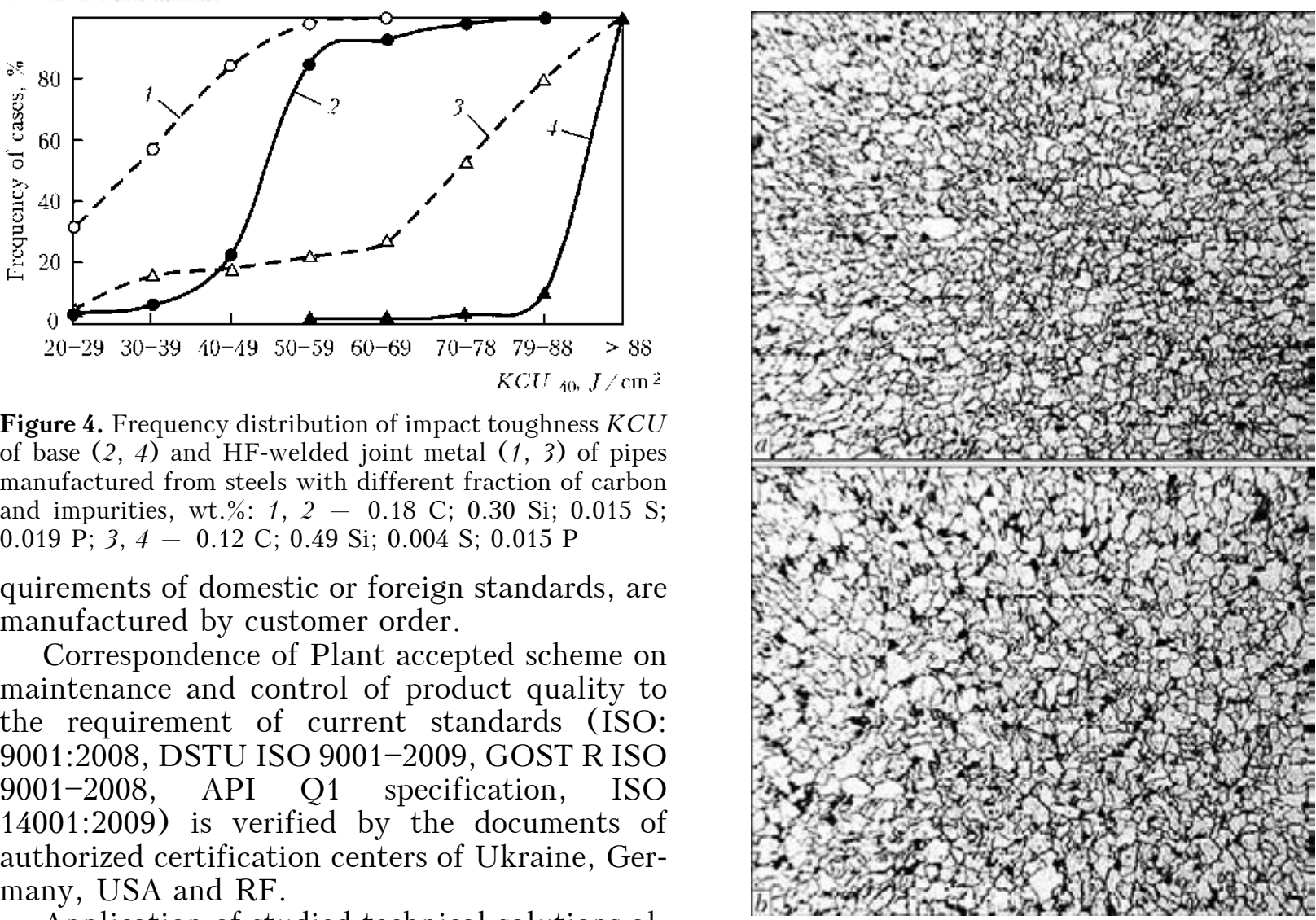

Figure 4. Frequency distribution of impact toughness $K C U$ of base $(2,4)$ and HF-welded joint metal $(1,3)$ of pipes manufactured from steels with different fraction of carbon and impurities, wt.\%: 1, 2-0.18 C; $0.30 \mathrm{Si} ; 0.015 \mathrm{~S}$; $0.019 \mathrm{P} ; 3,4-0.12 \mathrm{C} ; 0.49 \mathrm{Si} ; 0.004 \mathrm{~S} ; 0.015 \mathrm{P}$

quirements of domestic or foreign standards, are manufactured by customer order.

Correspondence of Plant accepted scheme on maintenance and control of product quality to the requirement of current standards (ISO: 9001:2008, DSTU ISO 9001-2009, GOST R ISO 9001-2008, API Q1 specification, ISO 14001:2009) is verified by the documents of authorized certification centers of Ukraine, Germany, USA and RF.

Application of studied technical solutions allowed significantly expanding schedule of produced HF-welded pipes at providing their high service reliability. In recent years, Plant workshop for electric welding of pipes repeatedly manufactured gas-and-oil line pipes of 159$530 \mathrm{~mm}$ diameter of different grade schedule, including strength category from L245 to L415 on EN 10208-2, B and from X42 to X70 on API 5L PSL2 (now ANSI/API Spec 5L/ISO

Figure 5. Microstructure $(\times 200)$ of base $(a)$ and welded joint metal (b) on K52 strength class pipe

3183:2007), and from K43 to K60 on standards or specifications of RF and Ukraine.

Coiled strip of optimum technical characteristics (chemical composition, mechanical properties, microstructure, geometry, quality, rolled surface) is used for manufacture of gasand-oil line pipes. Practice of pipe manufacture

Table 1. Results of tensile tests of pipe base metal

\begin{tabular}{|c|c|c|c|c|c|}
\hline $\begin{array}{l}\text { Design: pipe } \\
\text { symbolic code }\end{array}$ & $\begin{array}{l}\text { Steel grade, strength category, carbon } \\
\text { equivalent, manufacturer }\end{array}$ & $\begin{array}{l}\text { Dimension-type, } \\
\text { (reference document) }\end{array}$ & $\sigma_{y}, \mathrm{MPa}$ & $\sigma_{\mathrm{t}}, \mathrm{MPa}$ & $\delta_{5}, \%$ \\
\hline Standard: & & & & & \\
\hline A1 & 20, K42, 0.29, OJSC MMK & $\begin{array}{c}426 \times 6 \\
(\mathrm{TU} 14-3-377-99)\end{array}$ & $\frac{359-374(367)}{\geq 245}$ & $\frac{503-508(506)}{\geq 412}$ & $\frac{34-35(34.5)}{\geq 23}$ \\
\hline $\mathrm{A} 2$ & L360, MB, 0.33, OJSC «Severstal» & $\begin{array}{c}323.9 \times 8 \\
(\text { EN } 10208-2)\end{array}$ & $\frac{360-416(425)}{360-510}$ & $\frac{478-537(507)}{\geq 460}$ & $\frac{30-34(32)}{\geq 20}$ \\
\hline $\begin{array}{c}\text { Increased } \\
\text { strength: } \\
\text { B1 }\end{array}$ & 10G2FBYu, K60, 0.34, OJSC MMK & $\begin{array}{c}530 \times 10 \\
(\text { GOST R 52079-2003) }\end{array}$ & $\frac{537-540(539)}{\geq 451}$ & $\frac{604-620(612)}{\geq 590}$ & $\frac{27-29(28)}{\geq 20}$ \\
\hline $\mathrm{B} 2$ & $\mathrm{X} 70, P_{\mathrm{cm}}=0.16$, OJSC MMK & $\begin{array}{c}508 \times 8.7 \\
(\text { API 5L PSL2) }\end{array}$ & $\frac{493-500(496.5)}{485-635}$ & $\frac{618-635(626)}{570-760}$ & $\frac{33-34(33.5)}{\geq 26}$ \\
\hline $\begin{array}{l}\text { Cold- and corro- } \\
\text { sion-resistant: B }\end{array}$ & $\begin{array}{l}\text { 09GSF, K52, MB, 0.30, } \\
\text { OJSC «Severstal» }\end{array}$ & $\begin{array}{c}325 \times 9.5 \\
(\mathrm{TU} 1303-006.3- \\
593377520-2003)\end{array}$ & $\frac{355-395(375)}{353-510}$ & $\frac{620-635(628)}{\geq 510}$ & $\frac{34-36(35)}{\geq 20}$ \\
\hline
\end{tabular}


verifies a relevance of application of steel with reduced content of carbon and impurities for improvement of toughness characteristics of base and welded joint metal (Figure 4) [2, 3]. Current technologies of metallurgical production allow obtaining of coiled stock of a necessary strength level with fine-grained structure at reduced content of carbon in steel $[4,5]$. In particular, pipes of K52 strength class are manufactured from steel of $17 \mathrm{G} 1 \mathrm{~S}-\mathrm{U}$ type with limitation on content of carbon (not more than $0.14 \%$ ). Microstructure of base and welded joint metal of pipe from indicated steel are shown in Figure 5.

Tables 1-4 show, as an example, data on technical characteristics of metal of different types of HF-welded gas-and-oil line pipes of current «Interpipe NMPP» production. Data characterizing technical indices of corrosion-resistant coating are given in Table 5 . These examples verify that modernization of the enterprise process provided for the possibility of production of highquality HF-welded pipes for various service conditions of the main gas-and-oil pipelines.

High working capacity of HF-welded pipes, manufactured on modernized mill, is confirmed
Table 2. Results of tensile and static bending tests of metal of pipe welded joints

\begin{tabular}{|c|c|c|}
\hline $\begin{array}{c}\text { Pipe symbolic } \\
\text { code }\end{array}$ & $\sigma_{\mathrm{t}}, \mathrm{MPa}$ & Bending angle, flattening \\
\hline A1 & $\frac{556-564(560)}{\geq 412}$ & $\frac{180^{\circ} \text { (no cracks) }}{\text { Cracks are not allowed }}$ \\
\hline A2 & $\frac{493-536(514)}{\geq 460}$ & $\frac{\text { Flattening (no cracks) }}{\text { Cracks are not allowed }}$ \\
\hline B1 & $\frac{595-637(598)}{\geq 590}$ & $\frac{180^{\circ} \text { (no cracks) }}{\text { Cracks are not allowed }}$ \\
\hline B2 & $\frac{620-638(629)}{570-760}$ & $\frac{\text { Flattening (no cracks) }}{\text { Cracks are not allowed }}$ \\
\hline C & $\frac{595-637(598)}{\geq 510}$ & $\frac{180^{\circ} \text { (no cracks) }}{\text { Cracks are not allowed }}$ \\
\hline
\end{tabular}

Note. Grade of steel and pipe dimension-type in Tables 2-4 correspond to those in Table 1.

by the results of full-scale hydraulic testing. The E.O. Paton Electric Welding Institute carried out the investigations of a branch pipe (using internal pressure), cut out from $530 \times 8 \mathrm{~mm}$ pipe (17G1S-U steel), in a mode of low-cycle and further static loading up to failure. Tests, at in-

Table 3. Results of impact toughness tests of base metal and metal of pipe welded joints

\begin{tabular}{|c|c|c|c|c|}
\hline \multirow{2}{*}{ Pipe symbolic code } & \multirow{2}{*}{ Impact toughness index } & \multicolumn{2}{|c|}{ Base metal } & \multirow{2}{*}{$\begin{array}{l}\text { Impact toughness of weldec } \\
\text { joint metal }\end{array}$} \\
\hline & & Impact toughness & Portion of tough fracture, \% & \\
\hline A1 & $K C U_{-40}, \mathrm{~J} / \mathrm{cm}^{2}$ & $\frac{60-73(65)}{34.3}$ & $\mathrm{~N} / \mathrm{D}$ & $\frac{55-83(73)}{24.5}$ \\
\hline $\mathrm{A} 2$ & $K V_{0}, \mathrm{~J}$ & $\frac{120-298(209)}{\geq 40}$ & Same & $\frac{45-96(70.5)}{\geq 40}$ \\
\hline \multirow[t]{2}{*}{ B1 } & $K C V_{0}, \mathrm{~J} / \mathrm{cm}^{2}$ & $\frac{205-283(248)}{24.5}$ & 100 & $\frac{53-180(91)}{24.5}$ \\
\hline & $K C U_{-40}, \mathrm{~J} / \mathrm{cm}^{2}$ & $\frac{217-250(233)}{34.3}$ & 100 & $\frac{25-133(70)}{24.5}$ \\
\hline \multirow[t]{2}{*}{ B2 } & $K V_{0}, \mathrm{~J}$ & $\frac{127-140(132)}{\geq 27}$ & $\mathrm{~N} / \mathrm{D}$ & $\frac{40-44(41)}{\geq 27}$ \\
\hline & $K V_{-20}, \mathrm{~J}$ & $\frac{47-57(53)}{\geq 27}$ & Same & $\frac{29-32(31)}{\geq 27}$ \\
\hline $\mathrm{C}$ & $K C V_{-50}, \mathrm{~J} / \mathrm{cm}^{2}$ & $\frac{135-190(163)}{59}$ & $\frac{85-95(90)}{50}$ & $\frac{230-250(240)}{59}$ \\
\hline
\end{tabular}

Table 4. Results of corrosion resistance tests of 09GSF steel pipes (pipe symbolic code C)

\begin{tabular}{||c|c|c|c|c|c|}
\hline \multirow{2}{*}{$\begin{array}{c}\text { Rate of total corrosion, } \\
\mathrm{mm} / \text { year }\end{array}$} & \multicolumn{3}{|c|}{ Hydrogen cracking, \% } & \multirow{2}{*}{$\begin{array}{c}\text { Resistance to stress sulfide-induced cracking } \\
\left.\text { (at } \sigma_{\text {th }} / \sigma_{0.2} \geq 0.7\right)\end{array}$} \\
\cline { 2 - 5 } & \multicolumn{2}{|c|}{ Base metal } & \multicolumn{2}{|c|}{ Welded joint metal } \\
\cline { 2 - 5 } & $C L R$ & $C T R$ & $C L R$ & CTR & No fracture \\
\hline$\frac{0.327702}{\leq 0.5}$ & $0 / \leq 6$ & $0 / \leq 3$ & $0 / \leq 6$ & $0 / \leq 3$ & Without fracture of specimens \\
\hline
\end{tabular}

Note. Here $C L R, C T R$ are the coefficients of length and thickness of crack, respectively; $\sigma_{\text {th }}-$ the stress during testing of specimens on resistance to sulfide-induced cracking. 
INDUSTRIAL

Table 5. Results of tests of corrosion-resistant coatings of pipes manufactured on TU U 27.2-05393139-017:2008

\begin{tabular}{|c|c|c|c|c|c|}
\hline $\begin{array}{l}\text { Dimension- } \\
\text { type, mm }\end{array}$ & Coating structure, material (manufacturer) & $\begin{array}{l}\text { Coating } \\
\text { thickness, } \\
\mathrm{mm}\end{array}$ & $\begin{array}{l}\text { Dielectric uniformity, } \\
\mathrm{kV}\end{array}$ & $\begin{array}{l}\text { Impact strength, } \\
\mathrm{J} / \mathrm{mm}, \\
\text { at } T,{ }^{\circ} \mathrm{C}\end{array}$ & $\begin{array}{l}\text { Adhesion to steel, } \\
\mathrm{N} / \mathrm{cm}, \\
\text { at } T,{ }^{\circ} \mathrm{C}\end{array}$ \\
\hline $219 \times 7.0$ & $\begin{array}{l}\text { Double-layer, Trizolen } 200 \mathrm{U} \text { adhesive } \\
\text { (Germany), Alcudia } 380 \mathrm{~N} \text { polyethylene } \\
\text { (Leuna Euro-Kommerz GmbH) }\end{array}$ & $\frac{2.7}{2.0}$ & $\begin{array}{c}\text { No breakdown } \\
\frac{(\text { at } U=18.5 \mathrm{kV})}{5 \mathrm{kV} \text { per } 1 \mathrm{~mm} \text { of }} \\
\text { thickness }\end{array}$ & $\begin{array}{l}8.7 / 6,-40 \pm 3 \\
7.1 / 5,20 \pm 5 \\
5.2 / 3,60 \pm 3\end{array}$ & $\begin{array}{c}150 / 70,20 \pm 5 \\
80 / 30,60 \pm 3\end{array}$ \\
\hline $530 \times 8.0$ & $\begin{array}{l}\text { Three-layer, Corro-Coat EP-F2002 HW } \\
\text { epoxy powder (Jotun Powder Coatings, } \\
\text { Czech Republic); Coesive L } 8.92 .8 \\
\text { adhesive (Materie Plastiche Bresciane, } \\
\text { Italy), Luxene HDPE } 3450 \text { polyethylene } \\
\text { (Same) }\end{array}$ & $\frac{3.4}{2.2}$ & $\begin{array}{c}\text { No breakdown } \\
\frac{(\text { at } U=22.5 \mathrm{kV})}{5 \mathrm{kV} \text { per } 1 \mathrm{~mm} \text { of }} \\
\text { thickness }\end{array}$ & $\begin{array}{c}17.5 / 6,-40 \pm 3 \\
14.8 / 5,20 \pm 5 \\
7.4 / 3,60 \pm 3\end{array}$ & $\begin{array}{c}166 / 100,20 \pm 5 \\
115 / 50,60 \pm 3\end{array}$ \\
\hline
\end{tabular}

itial stage of loading, were carried out on the basis of 10,000 cycles at $0.5-0.9 \mathrm{MPa}$ pressure (loading frequency was 2 cycles per minute). Further, the pipe failed in a course of single loading. Pipe specimens withstood cyclic loadings without formation of cracks and leakages. It was determined in the process of static test that pipe metal yield began at $120 \mathrm{kgf} / \mathrm{cm}^{2}(11.8 \mathrm{MPa})$ pressure. Failure pressure made $172 \mathrm{kgf} / \mathrm{cm}^{2}(16.9 \mathrm{MPa})$ that 2.64 times exceeded service pressure. The fracture took place in a middle part of the specimen at $125 \mathrm{~mm}$ distance from the pipe weld.

Similar tests were carried out at Central RSI of Shipbuilding Technology (Moscow). Tested $530 \times 10 \mathrm{~mm}$ size pipe of K60 strength category withstood 10,000 cycles of loading at $90 \mathrm{kgf} / \mathrm{cm}^{2}$ (8.83 $\mathrm{MPa})$ maximum value of internal hydraulic pressure, that corresponds to the conditions of pipeline continuous duty. Then, the pipe was tested until fracture, which took place along base metal at $223 \mathrm{kgf} / \mathrm{cm}^{2}(21.9 \mathrm{MPa})$, that created loading at the level of base metal tensile strength.

Specimens of base and welded joint metal of pipes with increased corrosion resistance, manufactured from 09GSF and 13KhFA grade steels, were successfully tested by special organizations, namely Samara Engineering Center (RF) and Research-Tecting center «Kachestvo» (Dnepropetrovsk, Ukraine). At that, resistance to hydrogen and stress sulfide-induced cracking, as well as total corrosion rate, were evaluated. Indicated pipes are used for construction of commercial fields of OJSC TNK and others companies.

Possibility of manufacture of the pipes at the level of requirements of current world standards, providing of high operation capacity and ensuring of the guarantees of pipe quality and reliability served a basis for receiving of accreditation by the enterprise from authorized bodies, including USA, EU and RF, and rights for delivery of their products in the countries of near and far abroad for construction of main gas-and-oil pipelines.

\section{Conclusions}

1. Modernizing of technological process allowed «Interpipe NMPP» expanding schedule of HFwelded pipes manufactured for main gas-and-oil pipelines considering the requirements of current standards to their quality. In recent years, the Plant has mastered production and carries out regular deliveries of gas-and-oil line pipes of 159$530 \mathrm{~mm}$ diameter of different strength level (with standard ultimate strength up to $588 \mathrm{MPa}$ ) and designation (conventional design, cold- and corrosion-resistant) in accordance with the requirements of EU, USA, Ukraine, RF and other countries' standards. The Plant was granted a right by authorized centers of accreditation to delivery of the pipes for systems of main gas-and-oil pipelines, including in the far-abroad countries and RF.

2. Improved guarantees of stability in quality of HF-welded pipes are provided based on application of current technological equipment, complex of technological and acceptance control, as well as implementation of information technologies. Corresponding technical level of product quality management is verified by the documents from authorized international and domestic certification centers.

1. ANSI/API Spec. 5L/ISO 3183:2007: Specification for line pipe. Ed. 44. 1 Oct. 2007. Eff. data 1 Oct. 2008.

2. Antipov, Yu.N., Dmitrenko, E.V., Kovalenko, A.A. et al. (2009) Increase in service life of high-frequency welded pipes for main gas-and-oil pipelines. Problemy Prochnosti, 5, 147-153.

3. Rybakov, A.O., Semenov, S.E., Filipchuk, T.M. et al (2009) Increase of reliability of pipes for main pipelines. In: Problems of service life and safety of structures, constructions and machines. Kyiv: PWI, 383-387.

4. Denisov, S.V., Molostov, M.A., Stekanov, P.A. et al. (2008) Development of production technology of coiled stock from low-alloy steels for electric-welded pipes. Stal, 7, 65-68.

5. Morozov, Yu.D., Zikeev, V.N., Filatov, N.V. (2009) Development of coiled steels for electric welded (HFC) gas-and-oil, casing and pump-and-compressor pipes of higher strength, cold and corrosion resispipes of higher strength, cold 